\title{
Subgrouping University Students Based on Substance Use Pattern: A Latent Class Analysis
}

This article was published in the following Dove Press journal:

Substance Abuse and Rehabilitation

\author{
Mohammad Reza Karimirad' \\ Sima Afrashteh ${ }^{2,3}$ \\ Ali Gholami ${ }^{4,5}$ \\ Saeid Hossein Oghli ${ }^{6}$ \\ Abbas Abbasi-Ghahramanloo ${ }^{7}$ \\ Leila Bordbar ${ }^{8}$ \\ Mostafa Salari ${ }^{8}$ \\ 'Department of Psychiatric Nursing, \\ School of Nursing and Midwifery, Tehran \\ University of Medical Sciences, Tehran, \\ Iran; ${ }^{2}$ Department of Public Health, \\ School of Public Health, Bushehr \\ University of Medical Sciences, Bushehr, \\ Iran; ${ }^{3}$ Student Research Committee, \\ Shiraz University of Medical Sciences, \\ Shiraz, Iran; ${ }^{4}$ Noncommunicable Diseases \\ Research Center, Neyshabur University \\ of Medical Sciences, Neyshabur, Iran; \\ ${ }^{5}$ Department of Epidemiology \& \\ Biostatistics, School of Public Health, \\ Neyshabur University of Medical \\ Sciences, Neyshabur, Iran; ${ }^{6}$ Abhar \\ Branch, Islamic Azad University, Abhar, \\ Iran; ${ }^{7}$ Department of Public Health, \\ School of Health, Ardabil University of \\ Medical Sciences, Ardabil, Iran; \\ ${ }^{8}$ Department of Nursing, Hormozgan \\ University of Medical Science, Bandar \\ Abbas, Iran
}

Purpose: High-risk behaviors are the main causes of death and disability among youth and adults. Entering university might cause students to go through their first-hand experience of using substances.

Aim: This study aimed to detect the subgroups of students based on substance use and assess the effects of religiosity and parental support as well as other related factors on the membership of students in each latent class.

Methods: Using a multistage sampling method, this cross-sectional study was conducted in 2016 in Hormozgan University of Medical Sciences ( $n=524)$. All students completed a selfreport questionnaire. This questionnaire contained questions about substance use, religious beliefs and familial support. The questions of substance use were prepared using the World Health Organization Alcohol, Smoking and Substance Involvement Screening Test (WHO ASSIST). To analyze the data, PROC LCA statistical method was run in SAS9.2.

Results: Three latent classes were identified: 1) nonuser $(87.5 \%), 2)$ tobacco and illicit drug user (8.7\%) and 3) polydrug user (3.8\%). Having extramarital sex in the last month $(\mathrm{OR}=28.29,95 \% \mathrm{CI}$; 8.45-94.76), living alone (OR=4.29, 95\% CI; 1.01-18.35) and having a higher score of familial support $(\mathrm{OR}=0.94,95 \% \mathrm{CI}$; 0.89-0.98) were associated with the polydrug user class. Hookah smoking had the highest (11.1\%) and non-medical methylphenidate use had the lowest $(2.3 \%)$ prevalence among the participants of the study.

Conclusion: This study revealed that $12.5 \%$ of the students were either tobacco and illicit drug users or polydrug users. Thus, focusing on the religiosity and familial support may help design some preventive programs for this stratum of young adults.

Keywords: latent class analysis, substance use, religiosity, familial support, university students

\section{Introduction}

High-risk behaviors are the main causes of death and disability among youth and adults. The United Nations Office on Drug and Crime (UNODC) has reported that one-fourth of a billion 15-64-year-old people in the world used drugs at least once in $2016 .^{1}$

In the 21 st century, adolescents and youths have encountered multiple social changes that may contribute to potential substance use. ${ }^{2}$ One of the most important stages in the lives of these young adults can occur when they enter a university, which is associated with separation from family, facing peer pressures and exposure to new experiences, in turn leading to increased stress and behavioral problems such as substance use. Substance use can result in physical injuries and irreparable educational, psychological, socioeconomic and occupational failure. ${ }^{3,4}$
Correspondence: Abbas Abbasi-Ghahramanloo School of Health, Ardabil University of Medical Sciences, Daneshgah St, Ardabil 5618953141 , Iran

Tel +989145927737

Email abbasi.abbas49@yahoo.com

Substance Abuse and Rehabilitation 2020: I I 33-39 
Previous literature has already focused on the prevalence of substance use and its related factors as well as the introduction of high-risk groups and the consequences of engaging in substance use, but showing the possibility of simultaneous occurrence of different substances and the classification of students based on substance use are less taken into account. ${ }^{1,5,6}$

Although the trend of substance use is decreasing in European countries and the US, this issue has remained a major problem among young people and students in these countries. $^{7,8}$ Among Iranian students, the prevalence of substance use is relatively high. ${ }^{2,5}$ For example, in a study conducted in six universities in Tehran, a relatively high prevalence of hookah, smoking and alcohol use was reported. ${ }^{9}$

Important factors contributing to substance use include gender, high stress, the family history of substance use, family conflicts and protective factors such as religion, parental support and the high level of parental education. ${ }^{10-14}$ Religious beliefs have been identified as a protective factor against substance use. Prior studies have suggested that individuals with higher religiosity tend to demonstrate a range of healthy behaviors. ${ }^{15,16}$ Parental support is another factor that protects students against risky behaviors. Individuals from more cohesive families are less likely to try illegal drugs and substances. ${ }^{16,17}$ The relationship among the above-mentioned factors has been assessed by variable-centered studies considering each substance separately. As a result, there is no information on the association of these variables with the subgroups of substance use. For assessing the simultaneous effects of related factors on all types of substance, there are new approaches, one of which is Latent Class Analysis (LCA). LCA is a form of cluster analysis used as a tool to identify the latent subgroup specifications or classes of individuals with common characteristics. ${ }^{18}$

It should be noted that the prevalence of illicit drug and alcohol use among Iranian students could be different from other countries especially the western ones. Such a difference is mostly related to these factors: 1) religious and legal prohibition of alcohol and illicit drug use; 2) the cultural stigma against alcohol and illicit drug use and 3) the disapproval of alcohol and illicit drug by parents. ${ }^{12}$

Based on the above-mentioned introduction, this study aimed to investigate students' subgroups according to the substance use pattern using the LCA statistical method. Also, the effects of religious beliefs, familial support and some demographic characteristics on the probability of the membership of students in each class were evaluated.

\section{Methods}

\section{Study Population and Sampling Framework}

The present cross-sectional study was conducted in 2016 in Hormozgan University of Medical Sciences. To sample students, we used a multistage sampling scheme. This university has six faculties all of which were considered as strata. The proportion of students in different faculties was calculated (stratified sampling). Then, the number of classes was extracted. In the selection process, some classes were selected randomly in each faculty. In selected classes, all students were recruited to participate in the study. Finally, 580 students were invited to participate. Before the distribution of the questionnaires, the research team explained some needed explanations in each selected class on the aims of the study, the anonymity of the questionnaires and the voluntary nature of participation in the study. Moreover, the research team asked students not to include their names and other personal information in the questionnaire. To gain the students' trust and maintaining their confidentiality, pens with the same color were distributed among them to complete the questionnaire.

To obtain information about risk-taking behaviors, students completed a self-administrated questionnaire that was previously developed in another study ${ }^{19}$ in their class. More information on this questionnaire has been reported in previous studies. ${ }^{12,20}$

In this questionnaire, the questions designed to obtain information include the following topics: cigarette and hookah smoking, prescription-type opioids use, methylphenidate and sedative-hypnotics use, illicit drug use, having extramarital sex and some demographic characteristics.

To assess religious beliefs, a 28-item scale of Kendler's general religiosity was used. In this scale, a 5-point Likerttype scaling was used. As a result, the final score of religiosity for each student ranged between the minimum and maximum amounts (28 to 140 ). In this scoring system, the higher scores showed a higher level of religious beliefs. Parental support was assessed by the Persian version of Aneshensel and Sucoff's 13-item questionnaire. In this questionnaire, a 5-point Likert-type scaling was used. The final score of parental support for each student ranged between 13 to 65 (the lowest and highest scores) in which higher scores showed a higher level of parental support. More information about these two questionnaires has been provided in other studies. ${ }^{16,21}$ Extramarital sex has been 
defined as having sex with someone else out of marriage. As a result, extramarital sex includes having a sexual relationship with someone other than his/her spouse and also having pre-marital sex with someone.

The Ethics Committee of Hormozgan University of Medical Sciences approved the study. All students had signed an informed consent form.

\section{Statistical Analysis}

We used LCA to analyze the data. This approach is a latent categorical variable model that identifies individuals with similar characteristics and classifies similar participants. Considering the measurement error, this model assumes that the association of indicator variables (observed variables) could be stated by the categorization of the latent variable. LCA performs different iterations for all models of identified classes. Comparing the frequencies of response patterns (observed vs expected), LCA specifies the best model. This model calculates some indices that help select the best model such as $\mathrm{G}^{2}$, Akaike information criterion (AIC) and Bayesian information criterion (BIC). It should be noted that AIC and BIC are calculated based on the $\mathrm{G}^{2}$ statistic. For these criteria, a smaller value shows more goodness of the model. As a result, a model with the lowest value of AIC or BIC might be selected. In order to perform LCA in the current study, seven observed variables were used to assess the profile of substance use as a latent variable. These observable variables or indicators were cigarette and hookah smoking, alcohol use, prescription-type opioids use, methylphenidate use, sedativehypnotics and illicit drug use. To assess the role of some other related factors regarding clustering the students, after finalizing the model, we entered age, gender, having extramarital sex, living alone, religious beliefs and parental support into the LCA model as covariates. To perform all analyses, we used PROC LCA in SAS 9.2 software (SAS Institute Inc. Cary, NC, USA).

\section{Results}

From 580 distributed questionnaire, a total of $524(90.3 \%$ response rate) were completed by the students. The results showed that the mean age of the students was 23.0 \pm 4.2 . The lowest and highest age was 18 and 47 years old, respectively. Also, 58.2\% of the participants were male, and only a few were married (19.8\%).

Table 1 shows the prevalence of each substance use. This table indicates that among all students, hookah smoking in the last month had the highest prevalence among all types of substance. Likewise, non-medical methylphenidate use had the lowest prevalence. Besides, the results showed that men used more substances than women did.

Moreover, we fit the LCA models with different classes, ranging from one to eight. For each latent model, the needed indices were calculated. Table 2 shows these models. Given these indices and interpretability of the results of the models, we selected three latent-class models. Table 3 demonstrates the results of the three latentclass models of substance use pattern among students. This table contains three sections. The first section shows latent-class prevalence. The second one shows itemresponse probabilities, and the last one indicates odds ratios with a $95 \%$ confidence interval for covariates.

The second section of Table 3 contains the conditional probabilities of using each substance. It should be noted that the probability of non-using each substance can be calculated by subtracting the item response probabilities as shown in this table from 1. For labeling and interpreting each latent class, these item response probabilities were used. To show and highlight the overall pattern, the larger item response probabilities appear in bold font. For example, we named latent class 3 as "polydrug user" because this class was characterized by a high probability of using all substances. Similarly, latent class 1 was named as "non-user" and characterized by a low probability for using all substances. In contrast to these classes, another class showed a different pattern of substance use among students of this study. Latent class 2 was named as "tobacco and illicit drug user" and showed individuals high likely to smoke cigarettes and hookah along with illicit drug use.

The last section of Table 3 shows the odds ratio of membership in each latent class. We considered latent class 1 (non-user) as a reference class. This table indicates that having extramarital sex in the last month increased the odds of membership in latent class 2 and 3 compared to class 1. Similarly, living alone increased the odds of membership in latent class 2 and 3 compared to class 1 . In contrast to these two factors, having a higher familial support score decreased the odds of membership in latent class 2 and 3 compared to class 1. Although having a higher score of religiosity could decrease the membership in latent class 2 compared to class 1 .

\section{Discussion}

In this study, we examined substance use patterns and identified three latent classes among university students 
Table I Percentages of Students Responding "Yes" to Questions About Substance Use

\begin{tabular}{|l|l|l|l|l|l|l|}
\hline \multirow{2}{*}{ Items } & \multicolumn{2}{l|}{ Male (n=2 15) } & \multicolumn{2}{l|}{ Female (n=305) } & Total (n=524) \\
\cline { 2 - 7 } & $\mathbf{N}$ & $\%$ & $\mathbf{N}$ & $\%$ & $\mathbf{N}$ \\
\hline Cigarette smoking (last month) & 36 & 16.7 & 13 & 4.3 & 49 & 9.4 \\
Hookah smoking (last month) & 45 & 20.9 & 13 & 4.3 & 58 & 11.1 \\
Alcohol use (last month) & 24 & 11.2 & 12 & 3.9 & 36 \\
Prescription-type opioids use (last month) & 26 & 12.1 & 25 & 8.2 & 52 \\
Methylphenidate use (last month) & 8 & 3.7 & 4 & 1.3 & 12 & 9.9 \\
Sedative-hypnotics use (last month) & 15 & 7.0 & 17 & 5.6 & 3.9 \\
Illicit drugs use (life time) & 35 & 16.3 & 16 & 5.2 & 5.1 \\
\hline
\end{tabular}

in the city of Hormozgan. These three latent classes are the following: 1) Nonuser (87.5\%), 2) tobacco and illicit drug user $(8.7 \%)$ and 3$)$ polydrug user (3.8\%). Among the students belonging to the latent class 2 (tobacco and illicit drug user), the probability of cigarette and hookah smoking as well as illicit drug use was high. Also, among the students of the latent class 3 (polydrug users), the probability of engaging in all types of substance-related behavior was high.

Considering of the legal and religious prohibition of substance use in Iran and the negative stigma against substance use among Iranian people, it seems that a considerable number of students fell under "tobacco and illicit drug user" and "poly drug user" classes.

The results of multinomial regression indicated that a higher score of religiosity beliefs (only in tobacco and illicit drug user) and familial support decreased the odds of membership in the latent class 2 and 3 in comparison to the first class. In the previous variable and person-centered research, the preventive effect of religiosity on engaging in high-risk behaviors has been documented among university students. ${ }^{16,22-25}$ As for the person-centered studies, for example, Afrashteh et al showed that religious beliefs decrease the odds of membership in the high-risk class, somewhat high-risk class, hookah user class and very high-risk class compared to the low-risk class. ${ }^{25}$ Similarly, Mohammadpoorasl et al indicated that among male students, religious beliefs can decrease the odds of membership in the sexual and drinking risk takers class and high-risk class compared to the low-risk class. Previous research also demonstrates that among female students, a higher score of religiosity decreases the odds of membership in the cigarette and hookah smoker class, sexual risk-taker class and high risk class compared to the low-risk class. ${ }^{16}$
Additionally, this study revealed that familial support acts as a protective factor on the membership of students in second and third classes. The preventive role of familial support in substance-related behaviors have been reported in numerous variable-centered studies. ${ }^{21,26,27}$ But few studies have examined the effect of this factor on the personcentered analysis. ${ }^{16,25}$ For example, Afrashteh et al showed that familial support decreases the odds of membership in the high-risk class, somewhat high risk class, hookah user class and very high risk class compared to low-risk class. ${ }^{25}$

Religious beliefs and familial support could be considered as critical and influential factors in substance use preventive programs in university students. These factors along with other related variables can act as a marker for initiation of engaging in substance-related behaviors and finally for identification and implementation of the interventions among this stratum of the society.

Our results indicate that hookah smoking is a more common behavior compared to other substance-use behaviors. In the same vein, the results of national STEPS surveys have indicated that the prevalence of hookah smoking in Iranian adults ranges from 1.7 to $10.9 \%$ among men and from 0 to $16.8 \%$ among women. Besides, this study revealed that this behavior is common in the south and southeast of Iran. ${ }^{28}$ As can see in Table 3, hookah smoking cooccurred with other types of behavior and there is no specific class of students that only used hookah. Previous person-centered research in Iran has reported inconclusive findings. For instance, in a similar study in the south of Iran, Afrashteh et $\mathrm{al}^{25}$ reported that there is a specific group of students that are only hookah smokers. Nevertheless, other studies among students in Tabriz ${ }^{16}$ (the northwest of Iran) demonstrated that there is only one group of students (also in male and female students) that used cigarette and hookah 
Table 2 Comparison of LCA Models with Different Latent Classes Based on Model Selection Statistics

\begin{tabular}{|l|l|l|l|l|l|l|l|}
\hline $\begin{array}{l}\text { Number of Latent } \\
\text { Class }\end{array}$ & $\begin{array}{l}\text { Number of Parameters } \\
\text { Estimated }\end{array}$ & $\mathbf{G}^{2}$ & df & AIC & BIC & Entropy & $\begin{array}{l}\text { Maximum Log- } \\
\text { Likelihood }\end{array}$ \\
\hline 1 & 7 & 528.03 & 120 & 542.03 & 571.86 & 1.00 & -990.57 \\
2 & 15 & 103.18 & 112 & 133.18 & 197.10 & 0.94 & -778.14 \\
3 & 23 & 68.85 & 104 & 114.85 & 212.87 & 0.93 & -760.98 \\
4 & 31 & 59.53 & 96 & 121.53 & 253.64 & 0.92 & -756.32 \\
5 & 39 & 52.24 & 88 & 130.24 & 296.43 & 0.93 & -752.67 \\
6 & 47 & 45.48 & 80 & 139.48 & 339.77 & 0.84 & -749.29 \\
7 & 55 & 41.48 & 72 & 151.48 & 385.86 & 0.85 & -747.29 \\
8 & 63 & 34.39 & 64 & 160.39 & 428.86 & 0.72 & -743.75 \\
\hline
\end{tabular}

Abbreviations: LCA, latent class analysis; AIC, Akaike information criterion; BIC, Bayesian information criterion.

Table 3 The Three Latent Classes Model of Substance Use and Related Covariates

\begin{tabular}{|c|c|c|c|}
\hline & \multicolumn{3}{|l|}{ Latent Class } \\
\hline & Non User & Tobacco and Illicit Drug User & Poly Drug User \\
\hline Latent class prevalence & 0.875 & 0.087 & 0.038 \\
\hline \multicolumn{4}{|l|}{ Item-response probabilities } \\
\hline Cigarette smoking (last month) ${ }^{\mathrm{a}}$ & 0.007 & $0.730^{\mathrm{b}}$ & 0.630 \\
\hline Hookah smoking (last month) & 0.036 & 0.599 & 0.713 \\
\hline Alcohol use (last month) & 0.007 & 0.391 & 0.736 \\
\hline Prescription-type opioids use (last month) & 0.070 & 0.117 & 0.723 \\
\hline Methylphenidate use (last month) & 0.002 & 0.023 & 0.501 \\
\hline Sedative-hypnotics use (last month) & 0.026 & 0.096 & 0.774 \\
\hline Illicit drugs use (life time) & 0.019 & 0.505 & 0.953 \\
\hline Covariates & OR $(95 \% \mathrm{CI})$ & OR $(95 \% \mathrm{Cl})$ & OR $(95 \% \mathrm{Cl})$ \\
\hline Age $(p=0.800)$ & Reference & $1.01(0.95-1.07)$ & $1.07(0.96-1.19)$ \\
\hline Gender (being male) $(p<0.00 I)$ & Reference & $3.47(1.99-6.06) c$ & I.7I $(0.55-5.37)$ \\
\hline Having extra marital sex (last month) $(p<0.00 I)$ & Reference & $4.37(1.49-12.87)^{c}$ & $28.29(8.45-94.76)^{\mathrm{c}}$ \\
\hline Living alone $(p=0.002)$ & Reference & $5.41(2.29-12.83)^{\mathrm{c}}$ & $4.29(1.01-18.35)^{c}$ \\
\hline Religious beliefs $(\mathrm{p}=0.007)$ & Reference & $0.97(0.96-0.99)^{c}$ & $1.02(0.99-1.07)$ \\
\hline Familial support $(p=0.026)$ & Reference & $0.97(0.94-0.99)^{c}$ & $0.94(0.89-0.98)^{c}$ \\
\hline
\end{tabular}

Notes: The probability of a "No" response can be calculated by subtracting the item-response probabilities shown above from I. "Probability of a "Yes". 'Item-response probabilities $>0.5$ in bold to facilitate interpretation. "Significant OR.

simultaneously. Likewise, research has shown that among students of medical sciences in Tehran (the capital of Iran) there was not a separated group of hookah smoker. ${ }^{29}$ Yet, a study conducted in the U.S indicates that hookah smoking commonly cooccurs with other risk-taking behaviors, and there is no heterogenic group of students that use only hookah in the LCA model. ${ }^{30}$

Previous variable-centered research has revealed that individuals who are hookah smokers are more likely to engage in using marijuana, cigarettes, alternative tobacco products and alcohol. ${ }^{31-33}$ However, consistent with other person-centered studies from
Iran, ${ }^{16,25}$ this study showed that this may not be true for all hookah smokers. In other words, only the polydrug user class had the highest risk. In the second class, hookah users were at the risk of using cigarettes and illicit drugs and not all behaviors.

In line with to prior studies, ${ }^{34,35}$ the present study showed that hookah smoking exceeded cigarette smoking. The higher prevalence of hookah smoking can be due to the following reasons: age, availability and social setting and acceptance. Hookah smoking is more likely to be reported by younger students. Similarly, hookah smoking is a social activity for most young adults. For this reason, 
many hookah smokers have reported using hookah while hanging out with others. ${ }^{34,36,37}$

The majority of hookah users think that this behavior is less lethal and addicting than cigarettes or other types of substance. ${ }^{38}$ Cobb et al suggested that hookah smoking analysis, user toxicant exposure and health effect research could contradict this misperception about hookah. ${ }^{39}$ Unfortunately, there is no formal and legal instruction or prohibition against hookah smoking in Iranian universities.

As previously mentioned, this study evaluated the substance use pattern in university students. We also assessed the effects of parental support and religiosity as well as other related factors on the membership of the students in various latent classes that were identified by the LCA model. The findings of this study showed that most of the students are nonusers. But about $9 \%$ and $4 \%$ are tobacco and illicit drug users and polydrug users, respectively. Based on the findings, focusing on the religiosity and familial support may help design preventive interventional programs for reducing substance use prevalence in university students. Such programs could be used in lower ages such as high school students.

The strengths of this study were its good sampling scheme, acceptable sample size and high response rate. This study had some limitations, though. The first limitation was using a self-administrated questionnaire which could lead to the underestimation of the prevalence rates. Additionally, due to the cross-sectional nature of the present study, causality could not be assessed. Another setback was associated with assumptions of the LCA model. One of the most important assumptions of this model is the local independence of indicator variables. It is probable that this assumption was not established among different substances. Finally, the generalization of the findings of this study is limited to the students in the city of Hormozgan.

\section{Ethics Statement}

The present study was approved by Hormozgan University of Medical Sciences. Informed consent was confirmed by the Ethics committee and this study was conducted in accordance with Declaration of Helsinki.

\section{Disclosure}

The authors declare that there are no conflicts of interest for this work.

\section{References}

1. Sohrabivafa M, Tosang MA, Zadeh SZM, et al. Prevalence of risky behaviors and related factors among students of Dezful. Iran $J$ Psychiatry. 2017;12(3):188.

2. Rahmati-Najarkolaei F, Kamalikhah T. The comparative health-risk behaviors between boys and girls of freshmen at University of Tehran, Iran. Iran J Health Sci. 2014;2(3):15-23.

3. Eisenberg D, Gollust SE, Golberstein E, Hefner JL. Prevalence and correlates of depression, anxiety, and suicidality among university students. Am J Orthopsychiat. 2007;77(4):534-542.

4. Elbialy AAA, El-Shafie IF, Soliman FE-S. Risk taking behaviors among nursing students. IOSR-JNHS. 2017;6(5):70-78.

5. Heydari ST, Izedi S, Sarikhani Y, et al. The prevalence of substance use and associated risk factors among university students in the city of Jahrom, Southern Iran. Int J High Risk Behav Addict. 2015;4(2). doi:10.5812/ijhrba.4(2)2015.22381.

6. Bakar C, Gündogar D, Ozisik Karaman HI, Maral I. Prevalence and related risk factors of tobacco, alcohol and illicit substance use among university students. Eur J Psychiatry. 2013;27(2):97-110.

7. Johnston LD, O'Malley PM, Bachman JG, Schulenberg JE, Miech RA. Monitoring the Future National Survey Results on Drug Use, 1975-2015: Volume 2, College Students and Adults Ages 19-55. Ann Arbor: University of Michigan Institute for Social Research; 2015.

8. Hibell B, Guttormsson U, Ahlström S, et al. The 2015 ESPAD Report: Substance Use Among Students in 36 European Countries. Swedish Council for Information on Alcohol and other Drugs Stockholm; 2015.

9. Taremian F, Bolhari J, Pairavi H, Ghazi Tabatabaeii M. The prevalence of drug abuse among university students in Tehran. Iran $J$ Psychiatry Clin Psychol. 2008;13(4):335-342.

10. Haghdoost A, Abazari F, Abbaszadeh A, Rabori ED. Family and the risky behaviors of high school students. Iran Red Crescent Med J. 2014;16(10).

11. Pengpid S, Peltzer K, Mirrakhimov EM. Prevalence of health risk behaviors and their associated factors among university students in Kyrgyzstan. Int J Adolesc Med Health. 2014;26(2):175-185.

12. Abbasi-Ghahramanloo A, Fotouhi A, Zeraati H, Rahimi-Movaghar A. Prescription drugs, alcohol, and illicit substance use and their correlations among medical sciences students in Iran. Int J High Risk Behav Addict. 2015;4(1).

13. MohammadPoorasl A, Abbasi-Ghahramanloo A, Allahverdipour H, Esfeh JM. Prevalence of Hookah smoking in relation to religiosity and familial support in college students of Tabriz, northwest of Iran. $J$ Res Health Sci. 2014;14(4):268-271.

14. Allahverdipour H, Abbasi-Ghahramanloo A, Mohammadpoorasl A, Nowzari P. Cigarette smoking and its relationship with perceived familial support and religiosity of university students in Tabriz. Iran J Psychiatry. 2015;10(3):136.

15. Townsend M, Kladder V, Ayele H, Mulligan T. Systematic review of clinical trials examining the effects of religion on health. South Med J. 2002;95(12):1429-1435.

16. Mohammadpoorasl A, Ghahramanloo AA, Allahverdipour H. Risktaking behaviors and subgrouping of college students: a latent class analysis. Am J Men's Health. 2013;7(6):475-481.

17. Wills TA, Resko JA, Ainette MG, Mendoza D. Role of parent support and peer support in adolescent substance use: a test of mediated effects. Psychol Addict Behav. 2004;18(2):122.

18. Sharifi H, Mirzazadeh A, Noroozi A, et al. Patterns of HIV risks and related factors among people who inject drugs in Kermanshah, Iran: a latent class analysis. J Psychoact Drugs. 2017;49(1):69-73.

19. Amin-Esmaeili M, Yunesian M, Sahimi-Izadian E, Moinolghorabaei M, Rahimi-Movaghar A. The prevalence of illicit substance use among students of medical sciences in Tehran: results from four repeated surveys from 2006 to 2009. J Child Adolesc Subst Abuse. 2017;26(2):152-161. 
20. Amin-Esmaeili M, Rahimi-Movaghar A, Yunesian M, SahimiIzadian E, Moinolghorabaei M. Trend of smoking among students of Tehran University of Medical Sciences: results from four consecutive surveys from 2006 to 2009. MJIRI. 2013;27(4):168.

21. Farhadinasab A, Allahverdipour $H$, Bashirian $S$, Mahjoub $H$. Lifetime pattern of substance abuse, parental support, religiosity, and locus of control in adolescent and young male users. Iran $J$ Public Health. 2008;37(4):88-95.

22. Nabipour AR, Alizadeh A, Saadat-Hosseini M, Mansouri Z, Shamsoddini L, Nakhaee N. Correlates of waterpipe smoking among Iranian university students and the role of religiosity. Int $J$ Psychiat Med. 2016;51(6):494-507.

23. Deressa W, Azazh A. Substance use and its predictors among undergraduate medical students of Addis Ababa University in Ethiopia. BMC Public Health. 2011;11(1):660.

24. Peltzer K, Pengpid S, Amuleru-Marshall O, Mufune P, Zeid AA. Religiosity and health risk behaviour among university students in 26 low, middle and high income countries. JORH. 2016;55(6):21312140 .

25. Afrashteh S, Ghaem H, Abbasi-Ghahramanloo A. Clustering and combining pattern of high-risk behaviors among Iranian University students: a latent class analysis. J Res Health Sci. 2017;17(4).

26. Piko BF, Balázs MÁ. Authoritative parenting style and adolescent smoking and drinking. Addict Behav. 2012;37(3):353-356.

27. Ennett ST, Foshee VA, Bauman KE, et al. The social ecology of adolescent alcohol misuse. Child Dev. 2008;79(6):1777-1791.

28. Nemati S, Rafei A, Freedman ND, Fotouhi A, Asgary F, Zendehdel K. Cigarette and water-pipe use in Iran: geographical distribution and time trends among the adult population; a pooled analysis of national STEPS surveys, 2006-2009. Arch Iran Med. 2017;20(5).

29. Abbasi-Ghahramanloo A, Rahimi-Movaghar A, Zeraati H, Fotouhi A. Pattern of substance use among students of medical sciences in Tehran, Iran: a latent class analysis. J Subst Use. 2018;23(6):648654.
30. Evans-Polce R, Lanza S, Maggs J. Heterogeneity of alcohol, tobacco, and other substance use behaviors in US college students: a latent class analysis. Addict Behav. 2016;53:80-85.

31. Goodwin RD, Grinberg A, Shapiro J, et al. Hookah use among college students: prevalence, drug use, and mental health. Drug Alcohol Depend. 2014;141:16-20.

32. Hampson SE, Tildesley E, Andrews JA, Barckley M, Peterson M. Smoking trajectories across high school: sensation seeking and hookah use. Nicotine Tob Res. 2013;15(8):1400-1408.

33. Fielder RL, Carey KB, Carey MP. Hookah, cigarette, and marijuana use: a prospective study of smoking behaviors among first-year college women. Addict Behav. 2013;38(11):2729-2735.

34. Barnett TE, Smith T, He Y, et al. Evidence of emerging hookah use among university students: a cross-sectional comparison between hookah and cigarette use. BMC Public Health. 2013;13(1):302.

35. Primack BA, Fertman CI, Rice KR, Adachi-Mejia AM, Fine MJ. Waterpipe and cigarette smoking among college athletes in the United States. J Adolesc Health. 2010;46(1):45-51.

36. Smith JR, Novotny TE, Edland SD, Hofstetter CR, Lindsay SP, A1Delaimy $W K$. Determinants of hookah use among high school students. Nicotine Tob Res. 2011;13(7):565-572.

37. Ward KD, Eissenberg T, Gray JN, Srinivas V, Wilson N, Maziak W. Characteristics of US waterpipe users: a preliminary report. Nicotine Tob Res. 2007;9(12):1339-1346.

38. Smith-Simone S, Maziak W, Ward KD, Eissenberg T. Waterpipe tobacco smoking: knowledge, attitudes, beliefs, and behavior in two US samples. Nicotine Tob Res. 2008;10(2):393-398.

39. Cobb C, Ward KD, Maziak W, Shihadeh AL, Eissenberg T. Waterpipe tobacco smoking: an emerging health crisis in the United States. Am J Health Behav. 2010;34(3):275-285. doi:10.5993/ AJHB.34.3.3
Substance Abuse and Rehabilitation

\section{Publish your work in this journal}

Substance Abuse and Rehabilitation is an international, peerreviewed, open access journal publishing original research, case reports, editorials, reviews and commentaries on all areas of addiction and substance abuse and options for treatment and rehabilitation. The manuscript management system is completely online and includes a very quick and fair peer-review system. Visit http://www.dovepress com/testimonials.php to read real quotes from published authors. 